\title{
Conflito de uso do solo em Áreas de Preservação Permanente da Bacia Hidrográfica do rio Marapanim, nordeste do Pará
}

\author{
Conflict of land use in Permanent Preservation areas of the Marapanim \\ River Basin, northeastern Pará
}

\author{
Ádanna de Souza Andrade' ${ }^{(0)}$, Suezilde da Conceição Amaral Ribeiro"1(D,

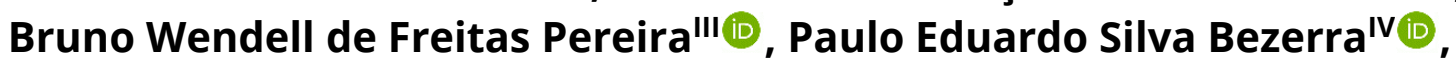 \\ Valter Vinicius Pereira Brandãov \\ 'Instituto Federal do Pará, Itaituba, PA, Brasil \\ "Universidade do Estado do Pará, Departamento de \\ Tecnologia de Alimentos, DETA, Belém, PA, Brasil \\ I" Universidade Federal Rural da Amazônia, Belém, PA, Brasil \\ IV Universidade Federal do Pará, Belém, PA, Brasil \\ ${ }^{\vee}$ Secretaria de Estado de Educação do Estado do Pará, Belém, PA, Brasil
}

\section{RESUMO}

As Áreas de Preservação Permanente (APP) têm papel fundamental na manutenção da qualidade dos recursos hídricos, bem como na proteção contra eventos erosivos. O objetivo desse trabalho é analisar o conflito de uso da terra nas áreas de preservação permanente da bacia hidrográfica do rio Marapanim, localizada no nordeste do Estado do Pará. Para alcançar esse objetivo, foram obtidas imagens do satélite Landsat dos anos de 1988, 1998, 2008 e 2017 e realizados processamentos a fim de se obter o uso e cobertura do solo para cada ano. Posteriormente, foi feita sobreposição do uso do solo com as Áreas de Preservação Permanente da bacia (APP's), visando assim, identificar as unidades de uso que estão interferindo nos limites que deveriam ser mantidos como APP. Os resultados mostraram que a ocupação irregular nas APP's aumentou em $46,57 \%$ do primeiro ao último ano de análise. Assim, esse estudo pode subsidiar a formulação de políticas públicas visando o monitoramento das nascentes e margens dos cursos d'água, promovendo assim, melhor gestão dos recursos hídricos dessa região.

Palavras-chave: Recursos hídricos; Geoprocessamento; Sistema de Informação Geográfica

\section{ABSTRACT}

Permanent preservation areas contribute significantly to maintaining the quality of water resources and protecting against erosive events. In this sense, this work mains of is to analyze the land use conflict in the permanent preservation areas of the Marapanim River basin, located in the northeast of the State of Pará. To this end, it data were processed using images Landsat of the years of 1988, 1998, 2008 and 2017 to discuss changes in land use for each year. Afterwards, land use was overlapped with the Permanent 
Preservation Areas of the basin (PPA), to identify the types of use that are interfering in the limits that should be maintained as PPA. The results showed that in three of the four years of analysis, the exposed soil class was present in more than $20 \%$ of the inadequate land use in PPA, followed by the Farming class, which increased almost 300\% the occupation in PPA in the first to last year of study. Thus, this study can support public policies in order to monitor the sources and margins of water courses for a better management of water resources in this region.

Keywords: Water resources; Geoprocessing; Geographic Information System

\section{INTRODUÇÃO}

As Áreas de Preservação Permanente (APP's), são definidas no código florestal (Lei 12.651/2012) como áreas protegidas, cobertas ou não por vegetação nativa, que possuem a função ambiental de preservar os recursos hídricos, a paisagem, o solo, a biodiversidade e assegurar o bem-estar das populações humanas (BRASIL, 2012).

Com a atual intensificação das ações antrópicas sobre o meio ambiente, as APP's estão sendo degradadas, devido a substituição das paisagens originais por outros usos e ocupações da terra, o que dá origem aos conflitos de uso nessas áreas (MOREIRA et al., 2015). Assim, os conflitos de uso da terra ocorrem quando há a implementação de novas formas de uso do solo em locais em que não há aptidão (no relevo ou solo, por exemplo) para essas atividades (notadamente a agropecuária), causando assim prejuízos ao ambiente (Kreitlow et al., 2016).

As APP's são de extrema importância ambiental e social no âmbito das bacias hidrográficas, já que propiciam a proteção dos recursos hídricos e a preservação da qualidade da água (CAMPAGNOLO et al., 2017). No entanto, fatores de ordem antrópica acabam interferindo no equilíbrio e funcionamento da bacia e consequentemente das APP's, ocasionando processos de degradação ambiental (SANTOS et al., 2014).

Almeida e Vieira (2014) destacaram que na Amazônia, a principal atividade responsável pela supressão da vegetação em áreas de preservação é a agropecuária, sendo essa atividade influenciada pelas práticas econômicas, culturais e sociais adotadas pelos produtores. Diversos são os impactos causados pela mudança de uso da terra em APP's, tais como alterações no balanço de água, erosão, assoreamento dos corpos hídricos, modificações no sistema ecológico e na qualidade da água, alterações no 
microclima e mudanças nos níveis de umidade do solo (OLIVEIRA et al., 2008; PINTO et al., 2005).

Devido à dimensão das bacias hidrográficas e a dificuldade de se dimensionar as áreas de preservação in loco, as ferramentas de geoprocessamento são imprescindíveis nos estudos envolvendo a análise do uso e ocupação do solo nas APP's, pois a partir da sobreposição de diversas informações espaciais, permite obter um diagnóstico dos conflitos de uso e da situação das APP's de acordo com a legislação ambiental vigente (CARDOSO e AQUINO, 2013; JUNIOR et al., 2010).

O sensoriamento remoto vem sendo amplamente utilizado não somente no Brasil, mas no mundo todo, aplicado notadamente ao monitoramento ambiental, principalmente a partir da utilização das imagens de satélite em análises multitemporais de uso e cobertura do solo e sua relação com a qualidade ambiental em bacias hidrográficas (BAKER e MILLER, 2013; ALEXAKIS et al., 2014; OLIVEIRA et al., 2018).

A Bacia hidrográfica do rio Marapanim, objeto deste estudo, está inserida no território do Nordeste Paraense, sendo essa mesorregião considerada uma das áreas mais antigas de colonização da Amazônia, na qual a construção da Estrada de Ferro Belém-Bragança no século XIX levou à descaracterização da vegetação original e à formação de um ambiente profundamente antropizado (VIEIRA et al., 2007). Considerando isso, a paisagem da bacia encontra-se muito fragmentada, como consequência das atividades antrópicas, com predominância de fragmentos pequenos e de forma irregular, portanto mais suscetíveis aos efeitos de borda (ANDRADE et al., 2020).

Nesse sentido, os conflitos de natureza hídrica que ocorreram e ainda ocorrem nessa região, levou ao reconhecimento, em março de 2017, pelo Conselho Estadual de Recursos Hídricos (CERH), do primeiro comitê de bacia do estado do Pará: O Comitê de Bacia Hidrográfica do Rio Marapanim (CBHRM), objetivando minimizar os impactos ambientais ao longo da bacia hidrográfica, através de ações, por exemplo, de recuperação de nascentes impactadas. Em setembro de 2019 o CBHRM foi instituído pelo Decreto n²88/2019 (PARÁ, 2019).

Assim, o objetivo desse trabalho é analisar, a partir das ferramentas de geoprocessamento, os conflitos de uso do solo nas áreas de preservação permanente da 
bacia hidrográfica do rio Marapanim-PA, visando assim, subsidiar as ações de monitoramento nas APP's da bacia, bem como prevenir impactos futuros.

\section{1 Área de estudo}

A bacia hidrográfica do rio Marapanim possui uma área de 2.141,26 km², faz parte da mesorregião nordeste paraense e abrange 12 municípios: Castanhal, Curuçá, Terra Alta, São Francisco, Igarapé-Açu, Maracanã, Magalhães Barata, Santa Izabel do Pará, Santo Antônio do Tauá, São Caetano, Vigia de Nazaré e Marapanim. Está localizada entre as coordenadas geográficas 0³2'19.075" e 1²18'36.961"S e 47³1'45.232" e 48²'20.954"W (Figura 1).

Figura 1 - Localização da área de estudo

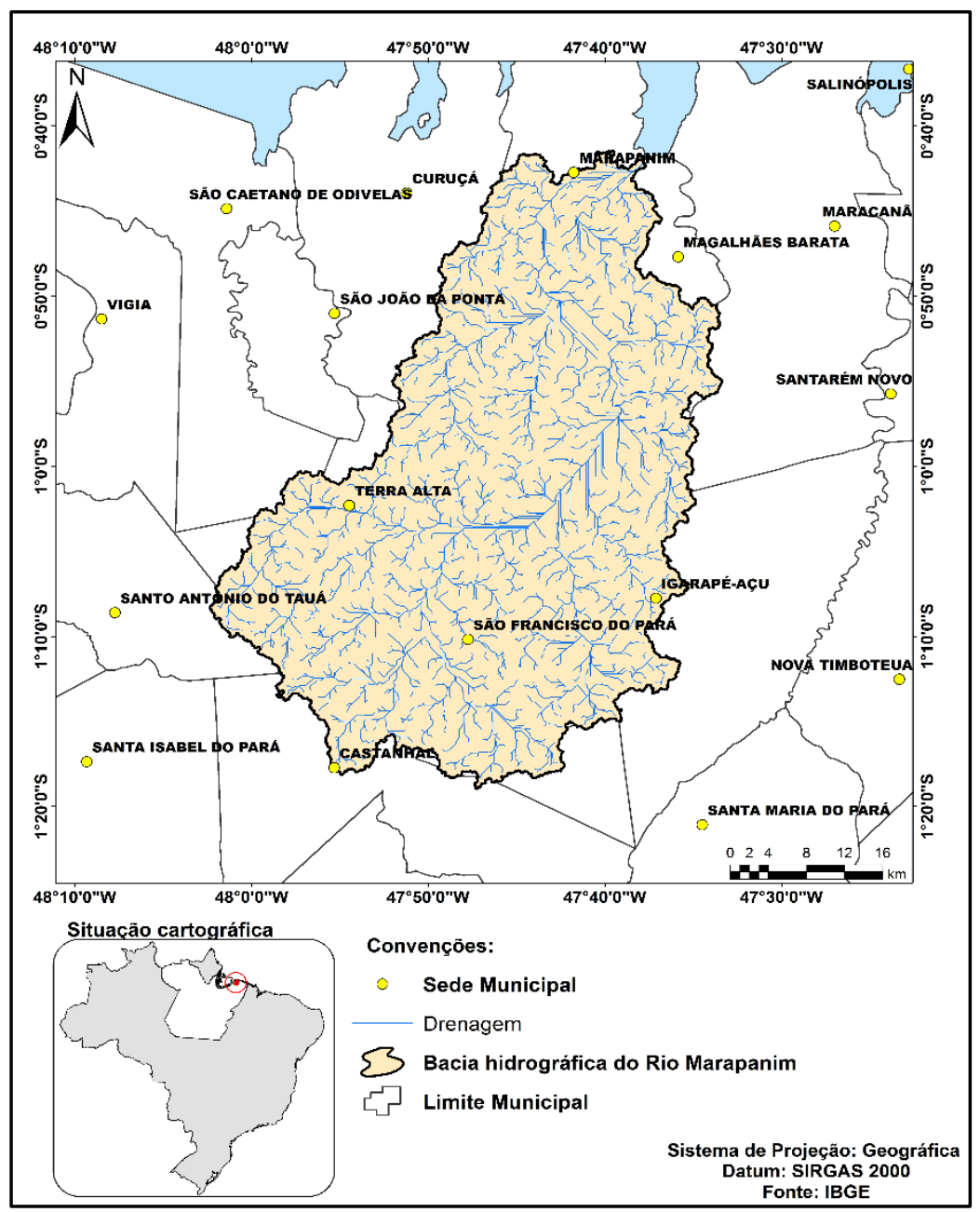

Fonte: Autores 


\section{MATERIAL E MÉTODOS}

O presente estudo foi realizado seguindo a metodologia mostrada no fluxograma da Figura 2. Cada etapa da metodologia está descrita e detalhada nos subitens que seguem.

Figura 2 - Fluxograma da metodologia do estudo

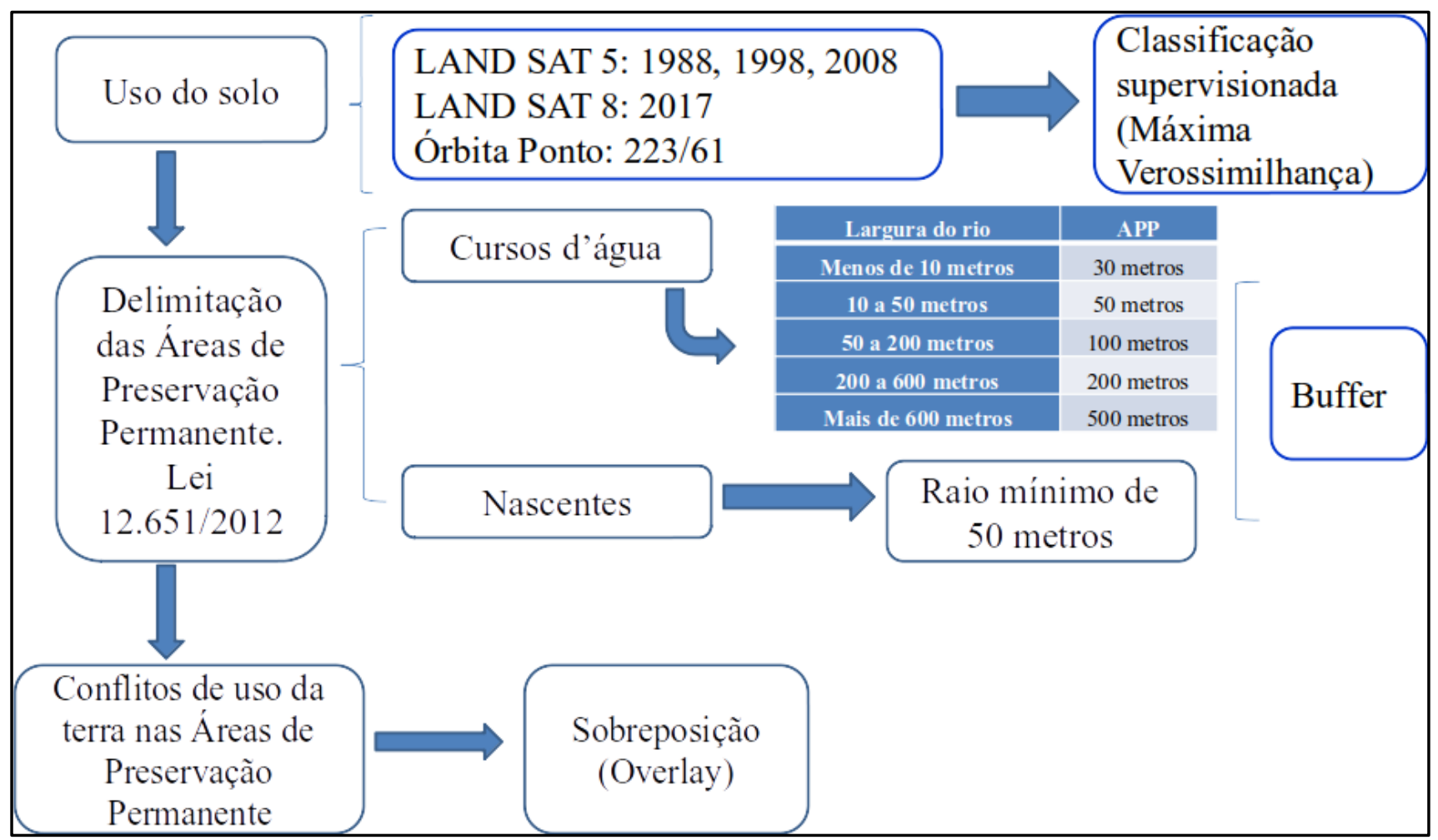

Fonte: Autores

\subsection{Aquisição e análise dos dados}

A delimitação dessa bacia foi realizada em Sistema de Informação Geográfica (SIG) utilizando-se dados do Shuttle Radar Topography Mission (SRTM), com resolução espacial de 30 metros, obtidas no banco de dados Topodata do Instituto Nacional de Pesquisas Espaciais, por meio de imagens do tipo Modelo Digital de Elevação (MDE) de número 00S48ZN e 01S48ZN articulada às cartas na escala 1:250.000. A delimitação da bacia e da rede hidrográfica foi realizada utilizando-se o complemento GRASS do software QGIS versão 2.18. 
Essa bacia tem como rio principal o rio Marapanim, que possui 127,96 km de extensão e abrange um território ocupado por 532.528 habitantes (IBGE, 2010). De acordo com Alvares et al. (2014), o clima dessa mesorregião é do tipo "Am" (Monção) baseado na classificação de Koppen. A precipitação média anual varia entre 2500 $\mathrm{mm}$ e $3000 \mathrm{~mm}$ e temperatura média anual em torno de $26,5^{\circ} \mathrm{C}$ (MARTORANO et al., 1993).

De acordo com IBGE (2012) a floresta original é do tipo floresta ombrófila densa de terras baixas, formação que em geral ocupa as planícies costeiras. Os solos predominantes são os latossolos amarelos distróficos, ou seja, de baixa fertilidade natural (EMBRAPA, 2013).

\subsection{Uso e ocupação do solo}

O mapeamento do uso e ocupação do solo ao longo da bacia foi realizado para identificar as classes de uso que estão presentes na área, para posteriormente identificar as atividades que estão conflitando com os limites que deveriam estar mantidos preservados, de acordo com o que preconiza a legislação ambiental. Para o mapeamento do uso e ocupação do solo na bacia hidrográfica, foram obtidas no site do Serviço Geológico dos Estados Unidos (USGS), imagens do satélite Landsat 5 e 8, conforme especificações descritas na Tabela 1.

Tabela 1 - Imagens utilizadas no mapeamento de uso do solo

\begin{tabular}{ccccc}
\hline Ano & Data & Órbita/Ponto & Sensor & Satélite \\
\hline 1988 & $04 / 06 / 1988$ & $223 / 61$ & TM & Landsat 5 \\
1998 & $19 / 08 / 1998$ & $223 / 61$ & TM & Landsat 5 \\
2008 & $13 / 07 / 2008$ & $223 / 61$ & TM & Landsat 5 \\
2017 & $06 / 07 / 2017$ & $223 / 61$ & OLI & Landsat 8 \\
\hline
\end{tabular}

Fonte: Autores (2019)

Essas imagens foram pré-processadas em um ambiente SIG, submetidas a uma correção atmosférica pelo método DOS (Dark Object Subtration) proposto por Chavez (1988 e 1989), para corrigir o efeito do espalhamento atmosférico na radiância da cena. Na imagem Landsat 8, foi feita a transformação radiométrica (16 
para 8 bit) e assim, gerada a classificação de uso do solo, a partir da interpretação das bandas de reflectância 3, 4 e 5 do Landsat 5 e 4, 5 e 6 do Landsat 8, as quais geraram a composição colorida das imagens. Foi feito um recorte das cenas para a área de estudo, utilizando-se a máscara vetorial da delimitação da bacia hidrográfica.

Posteriormente, foi realizada a classificação supervisionada pelo método de Máxima Verossimilhança (Maxver), a qual trabalha com a probabilidade de uma célula pertencer a cada um dos conjuntos de classes pré-definidos, sendo atribuída à célula a classe de mais elevada probabilidade (NOVO, 2010). A acurácia do processo de classificação foi obtida a partir da análise da matriz de confusão e do índice Kappa, o qual apresentou valor 0.8727 para 1988, 0,8944 para 1998, 0,8840 para 2008 e 0,9350 para 2017. A interpretação do índice Kappa foi realizada a partir da classificação de Landis e Koch (1977), conforme a Tabela 2.

Tabela 2 - Qualidade da classificação baseada no índice Kappa

\begin{tabular}{lc}
\hline \multicolumn{1}{c}{ Coeficiente Kappa } & Qualidade da classificação \\
\hline$<0$ & Péssima \\
$0-0,2$ & Ruim \\
$0,21-0,4$ & Razoável \\
$0,41-0,6$ & Boa \\
$0,61-0,8$ & Muito boa \\
$0,81-1$ & Excelente \\
\hline
\end{tabular}

Fonte: Adaptado de Landis e Koch (1977)

\subsection{Delimitação das APP's}

Foram definidas as Áreas de Preservação Permanente do entorno dos cursos d'água e nascentes, levando-se em consideração a distância mínima que deve ser destinada à APP, prevista no código florestal. Assim, foram definidos trechos dos rios e medidas as larguras a fim de correlacionar com o que determina a legislação (Tabela 3). 
Tabela 3 - Faixas mínimas de APP

\begin{tabular}{lc}
\hline \multicolumn{1}{c|}{ Largura do rio } & APP \\
\hline Menos de 10 metros & 30 metros \\
10 a 50 metros & 50 metros \\
50 a 200 metros & 100 metros \\
200 a 600 metros & 200 metros \\
Mais de 600 metros & 500 metros \\
\hline
\end{tabular}

Fonte: Brasil, 2012

Para as nascentes, a legislação prevê que, qualquer que seja sua situação topográfica, deve-se ter um raio mínimo de 50 (cinquenta) metros de APP (BRASIL, 2012). A delimitação das APP's foi realizada por meio da geração da zona de tamponamento a partir do leito regular dos cursos d'água, utilizando-se para isso, a ferramenta buffer do software QGIS versão 2.18. A área total das APP's foi obtida a partir da junção de todos os polígonos delimitados pelos critérios descritos.

A legislação prevê, ainda, APP's de topos de morro, montanhas e serras e as encostas ou parte destas com declividade superior a $45^{\circ}$ (BRASIL, 2012). Para a geração do mapa de declividade, foi utilizada a altimetria do terreno a partir do arquivo SRTM e aplicada a classificação da EMBRAPA (2009), a qual considera 5 classes de declividade, variando de plano a montanhoso (Tabela 4), podendo ser visualizado a predominância de condições de baixa declividade (Figura 3).

Tabela 4 - Intervalos de declividade com as respectivas classes e o percentual ocupado na área da bacia

\begin{tabular}{lcc}
\hline \multicolumn{1}{c|}{ Intervalo de declividade (\%) } & Classe & Percentual ocupado na bacia \\
\hline 0 a 3 & Plano & $62,71 \%$ \\
3 a 8 & Suave ondulado & $34,41 \%$ \\
8 a 20 & Ondulado & 2,88 \\
20 a 45 & Forte ondulado & $0 \%$ \\
45 a 75 & Montanhoso & $0 \%$ \\
\hline
\end{tabular}

Fonte: Adaptado de EMBRAPA (2009) 
Figura 3 - Declividade da área de estudo

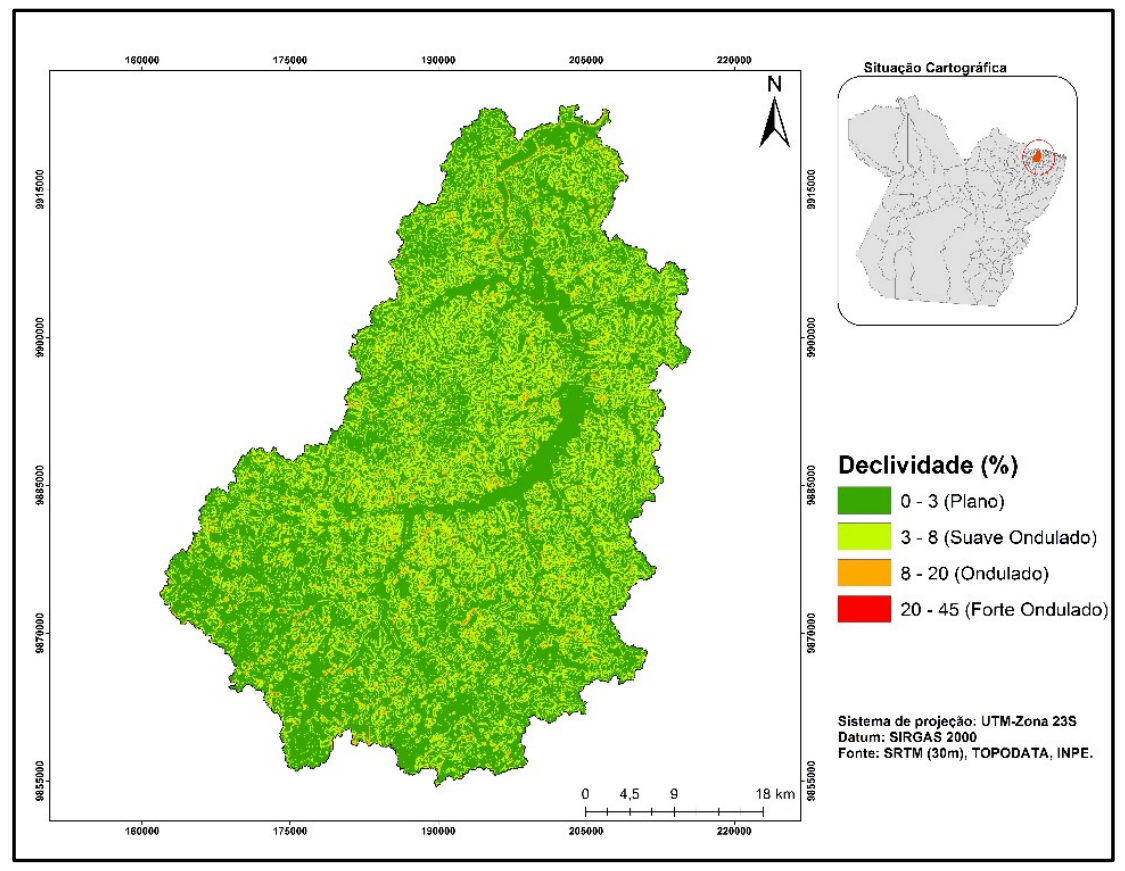

Fonte: Autores

Assim, a partir da Figura 3, pode-se constatar que na área de estudo há predominância de áreas com relevo plano e suave ondulado, não necessitando, portanto, de delimitação de APP's para topo de morros, serras, montanhas e encostas.

\subsection{Conflitos de uso do solo nas Áreas de Preservação Permanente}

Para a identificação das áreas de conflito de uso nas APP's, foi realizado uma sobreposição ou "overlay" do mapa das APP's com o mapa de uso e cobertura da terra obtido da área de interesse. Assim, no Sistema de Informação Geográfica (SIG) foi utilizada a ferramenta intersect, a qual interseccionou os dois layers e teve como resultado de saída um layer que apresenta apenas o que se sobrepõe nos layers de entrada. Tal procedimento delimitou as unidades de uso que estão interferindo nos limites considerados para APP's ao longo dos cursos d'água e ao redor das nascentes.

\section{RESULTADOS E DISCUSSÃO}

A área mínima de APP de cursos d'água que deveria existir na bacia hidrográfica é igual a $158,15 \mathrm{~km}^{2}$, o que corresponde a $7,38 \%$ da área da total da bacia. No que diz 
respeito às APP's de nascentes, essas deveriam ocupar $8,22 \mathrm{~km}^{2} \mathrm{da}$ área da bacia. No total, a bacia hidrográfica do rio Marapanim deveria ter 166,37 km² $^{2}$ de área preservada, o que corresponde a $7,76 \%$ da bacia (Figuras 4 e 5 ).

Figura 4 - Área de Preservação Permanente dos cursos d'água

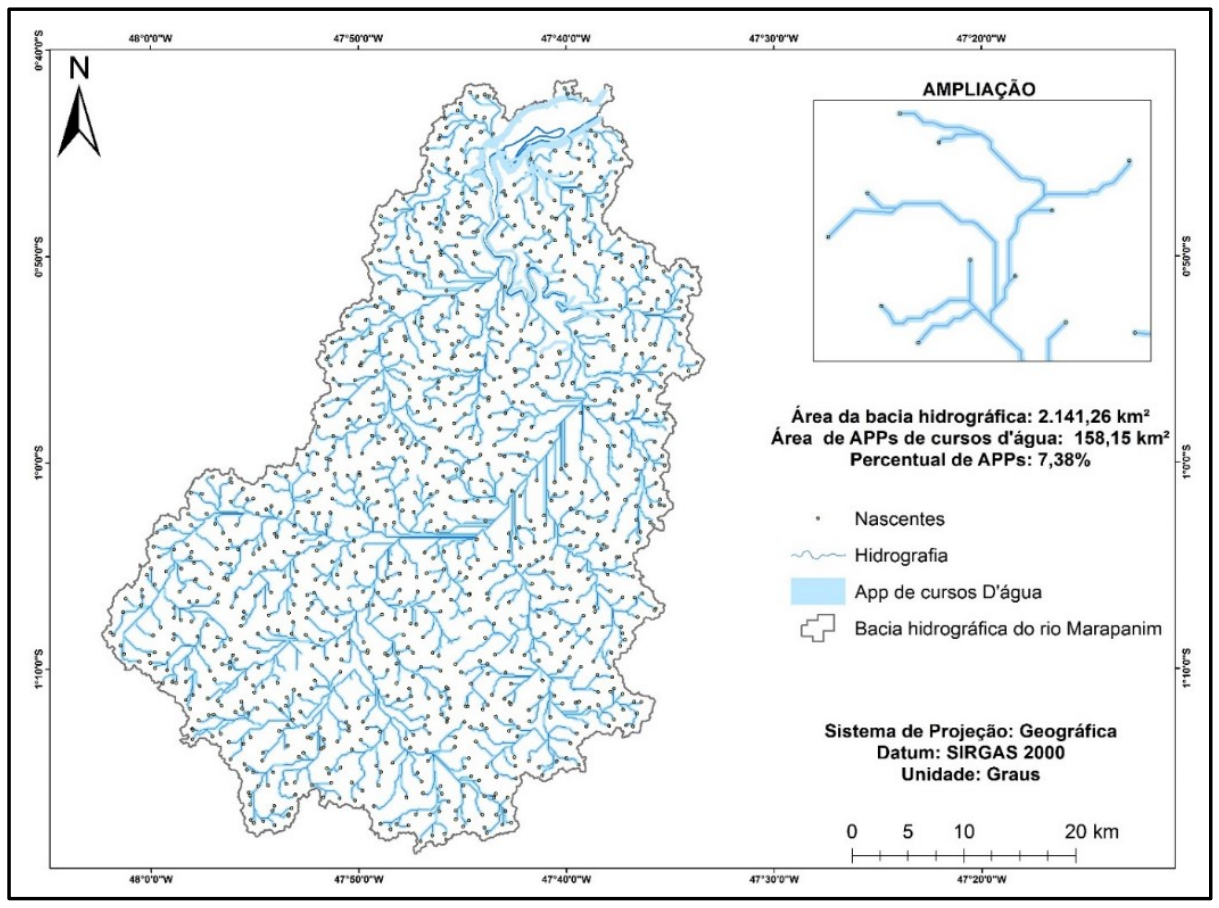

Fonte: Autores

Figura 5 - Área de Preservação Permanente das nascentes

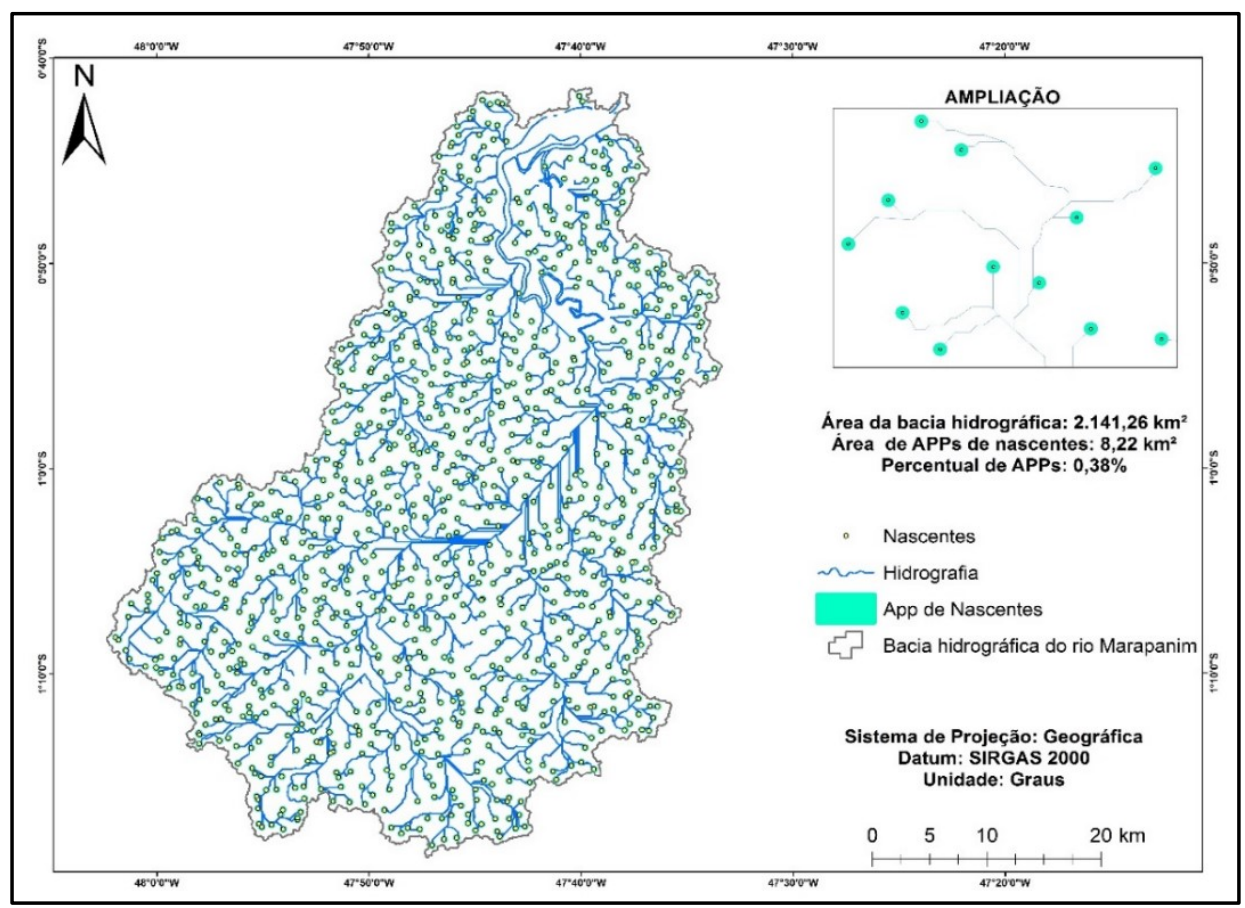

Fonte: Autores 
Com base na área mínima requerida de preservação permanente, fez-se a análise do conflito de uso do solo. As áreas de uso adequado incluíram floresta densa e vegetação secundária e as áreas de uso inadequado (conflitantes) incluíram agropecuária, solo exposto e áreas alteradas para todos os anos de análise (1988, 1998, 2008 e 2017). A classe áreas alteradas abrange áreas de degradação devido a intenso uso do solo, identificada espectralmente apenas nos dois últimos anos de análise. A Tabela 5 e a Figura 6 mostram a dinâmica das áreas ocupadas por cada classe em cada ano de estudo.

Tabela 5 - Dinâmica de uso e cobertura do solo nas Áreas de Preservação Permanente

\begin{tabular}{l|c|c|c|c|c|c|c|c}
\cline { 2 - 9 } \multicolumn{1}{c}{} & \multicolumn{2}{c}{1988} & \multicolumn{2}{c|}{ 1998 } & \multicolumn{2}{c|}{$\mathbf{2 0 0 8}$} & \multicolumn{2}{c}{$\mathbf{2 0 1 7}$} \\
\hline \multicolumn{1}{c}{ Classe } & Área & \% & Área & \% & Área & \% & Área & \% \\
\hline Vegetação secundária & 73,54 & 44,20 & 62,87 & 37,73 & 60,71 & 36,49 & 62,9 & 37,81 \\
Floresta densa & 48,86 & 29,37 & 56,15 & 33,72 & 49,33 & 29,65 & 43,62 & 26,22 \\
Solo exposto & 34,31 & 20,62 & 39,48 & 23,70 & 34,79 & 20,91 & 28,71 & 17,26 \\
Agropecuária & 6,52 & 3,92 & 5,81 & 3,51 & 19,65 & 11,81 & 25,76 & 15,48 \\
Áreas alteradas & - & - & - & - & 1,89 & 1,14 & 5,38 & 3,23 \\
Nuvem & 1,75 & 1,05 & 0,72 & 0,45 & - & - & - & - \\
Sombra & 1,39 & 0,84 & 1,34 & 0,89 & - & - & - & - \\
TOTAL & 166,37 & 100 & 166,37 & 100 & 166,37 & 100 & 166,37 & 100 \\
\hline
\end{tabular}

Fonte: Autores

Figura 6 - Área ocupada por cada classe de cobertura vegetal e uso do solo nas Áreas de Preservação Permanente

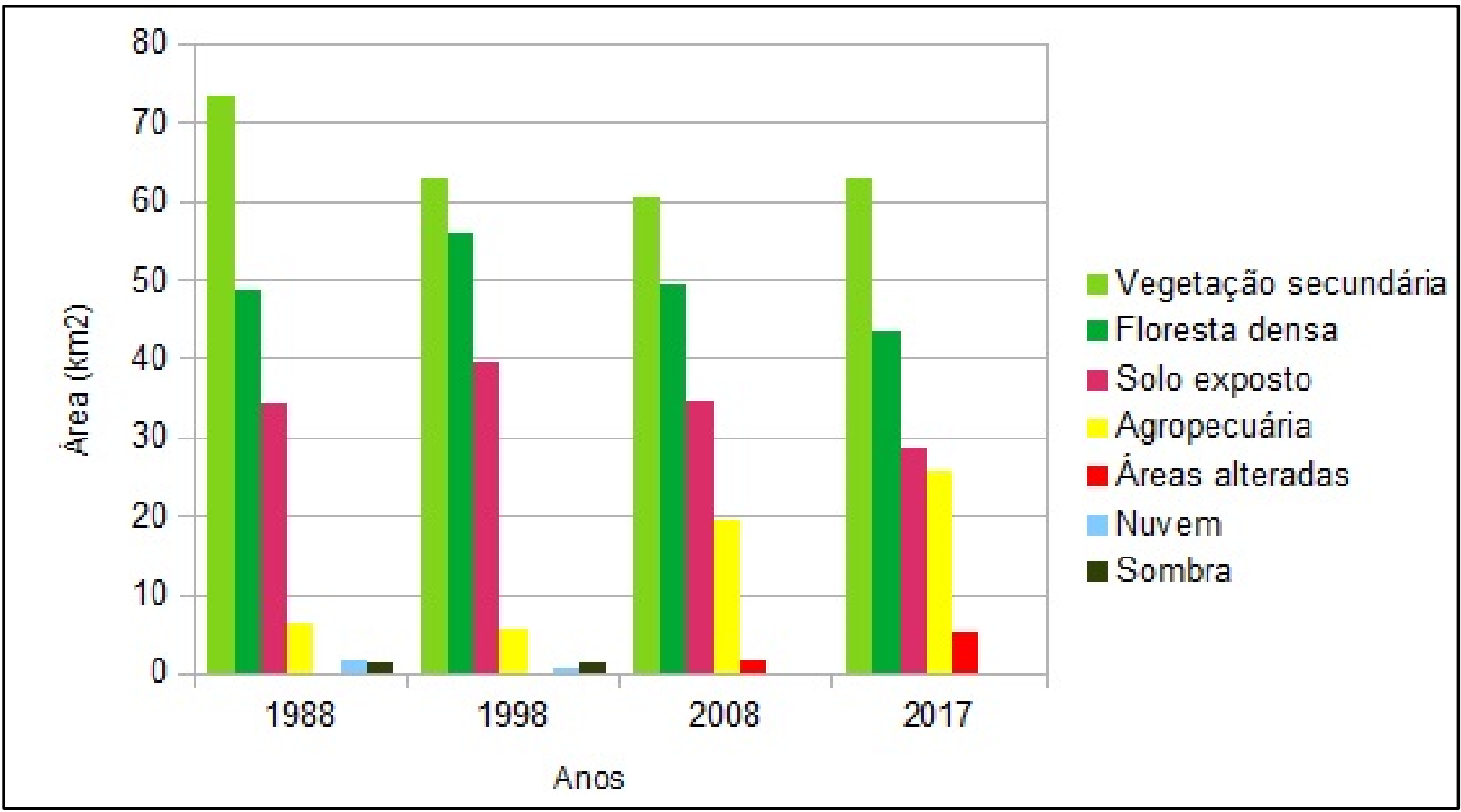

Fonte: Autores 
Em 1988 a maior parte das APP's era ocupada por vegetação secundária e densa, as quais somavam $73,57 \%$ das áreas ocupadas, valor ligeiramente inferior ao encontrado por Almeida e Vieira (2014) nas APP's do município de Moju, nordeste paraense em 2010 (73,73\%). Nesse ano, a maior parte das áreas conflitantes nas APP's da bacia eram ocupadas por solo exposto (20,62\%).

Uma década depois (1998), nota-se um pequeno aumento das APP's ocupadas por solo exposto $(23,70 \%)$, com um pequeno percentual das áreas ocupadas por agropecuária (3,51\%). No ano de 2008, verificou-se uma diminuição das áreas de solo exposto para 20,93\% e um aumento de mais de $200 \%$ das APP's ocupadas por agropecuária, que passou de 3,51 para 11,81 permanecendo com tendência de aumento para o ano de 2017, no qual essa classe ocupou 15,48\% das áreas que deveriam ser destinadas à preservação (Figura 7). Essa tendência de crescimento condiz com a realidade da dinâmica de uso e cobertura do solo no nordeste paraense, onde as áreas são ocupadas predominantemente por atividades agropecuárias, tal como observado por Watrin et al. (2007) e Venturieri et al. (2005).

Ao analisarem a dinâmica de desmatamento e a aplicabilidade das Áreas Prioritárias para Conservação (ACP) na bacia hidrográfica do rio Marapanim, Santos et al. (2019), constaram um quadro grave de supressão da cobertura vegetal e que 86\% da área da bacia é considerada como APC.

Borges et al. (2011) destacam que a abertura de novas áreas agrícolas em APP's pode comprometer a qualidade das águas superficial e subterrânea, a reposição de água nos aquíferos bem como causar a perda de solo e a degradação dos mananciais, comprometendo assim, a própria produção de alimentos. Além disso, há o risco de contaminação dos recursos hídricos pelos fertilizantes e pesticidas frequentemente utilizados na agricultura (COCCO et al., 2016). Assim, a preservação da mata ciliar propicia a preservação da qualidade da água do rio e diminui os impactos às margens, já que evita o acesso do gado ao leito do rio (Buck et al., 2004). 
Figura 7 - Uso e cobertura do solo nas áreas de preservação permanente da bacia hidrográfica nos anos de A) 1988, B) 1998, C) 2008 e D) 2017

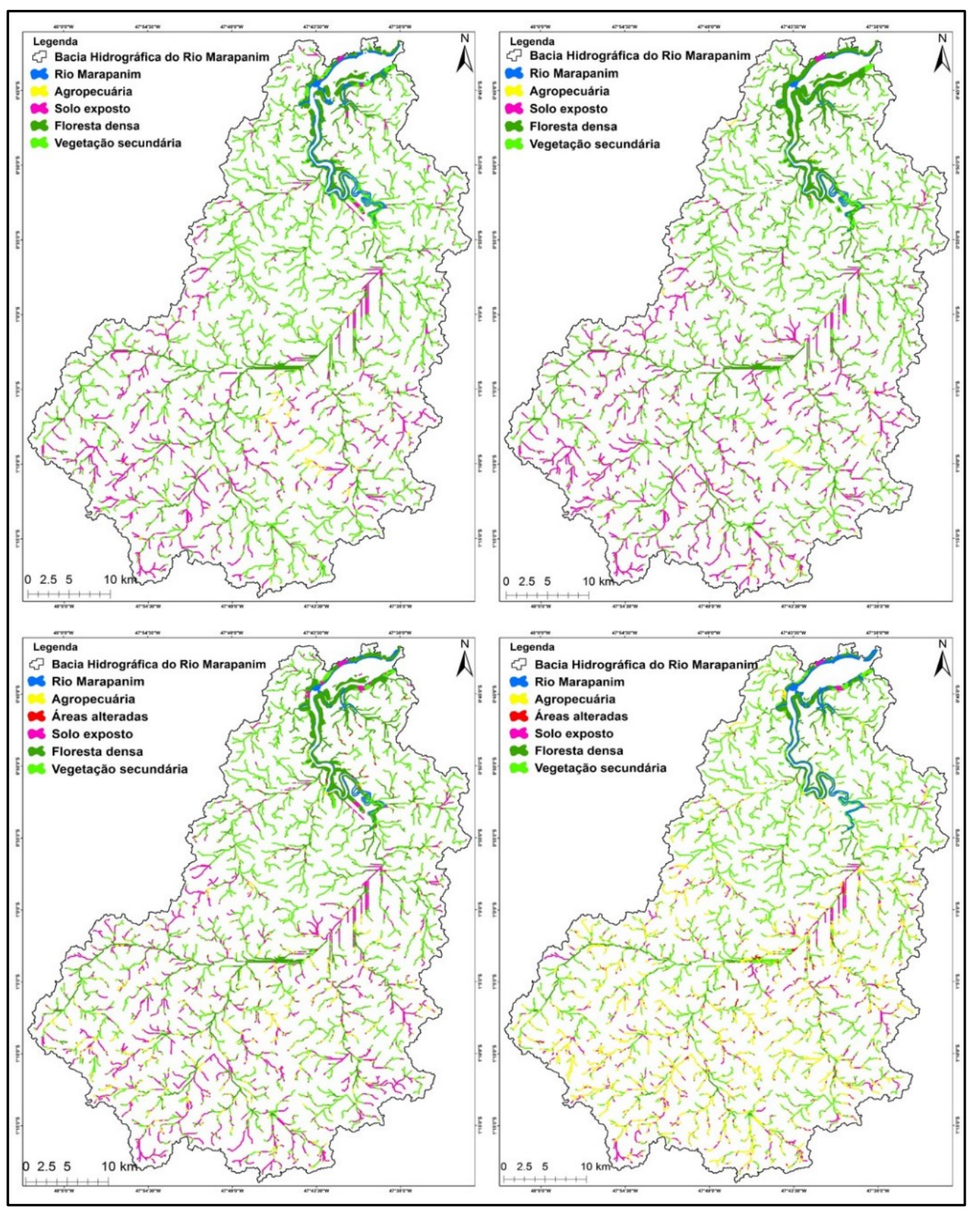

Fonte: Autores

A questão do uso agrícola em APP's foi estudada por Martini e Trentini (2011) ao enfatizarem que a incorporação de áreas agrícolas nas APP's deve-se entre outros fatores, ao fato da faixa de proteção ocupar terrenos incorporados à área total da propriedade, e nesse sentido, para o agricultor não existe irregularidade na utilização dessas áreas. Além disso o fato de que muitas vezes a ampliação da 
renda agrícola dá-se pela ampliação das áreas de cultivo ou pastagem, o que acaba pressionando as áreas de preservação.

Todavia, do primeiro ao último ano de análise, verifica-se que a classe conflitante que domina as ocupações das APP's é o solo exposto, caracterizado pela retirada completa da vegetação original onde deveria existir mata ciliar. Em um estudo realizado por Souza et al. (2012) no qual analisaram os conflitos de uso da terra nas APP's da bacia hidrográfica do rio Apeú, também no nordeste paraense, constataram que essa classe se fez presente entre 8 e 17\% das ocupações nos entornos dos cursos d'água e das nascentes durante os anos de 2001, 2004 e 2008. Entretanto, faz-se necessário destacar que as áreas de solo exposto podem estar associadas também à urbanização, reiterando assim, os impactos antrópicos na região.

De acordo com Cordeiro et al. (2017), as matas ciliares e nascentes do nordeste paraense foram desmatadas e hoje muitos rios encontram-se assoreados, o que afeta também a população local, já que há uma diminuição do pescado em decorrência da diminuição do nível do rio no período de estiagem.

Verifica-se a partir da Figura 7, que as áreas ocupadas por floresta densa em todos os anos concentram-se no entorno do rio Marapanim, na porção norte da bacia hidrográfica. De acordo com Ferreira et al. (2015) a manutenção da mata ciliar possibilita maior infiltração de água no solo e recarga dos aquíferos, além de proteger o recurso hídrico contra processos erosivos. A visualização de algumas nascentes impactadas (Figura 8) mostra os problemas de lixo jogado de forma irregular, como no igarapé do Pouso (Figura 7 B e D) localizado no médio curso da bacia, bem como o problema de assoreamento de corpo hídrico, na nascente do Rio das Pedras em Curuçá (Figura 7 A), no baixo curso da bacia. 
Figura 8 - Nascentes impactadas da bacia hidrográfica do rio Marapanim-PA. A) Nascente do Rio das pedras (Curuçá) B) e D) Igarapé do Pouso (São Francisco do Pará) C) Balneário Santo Antônio (Magalhães Barata)

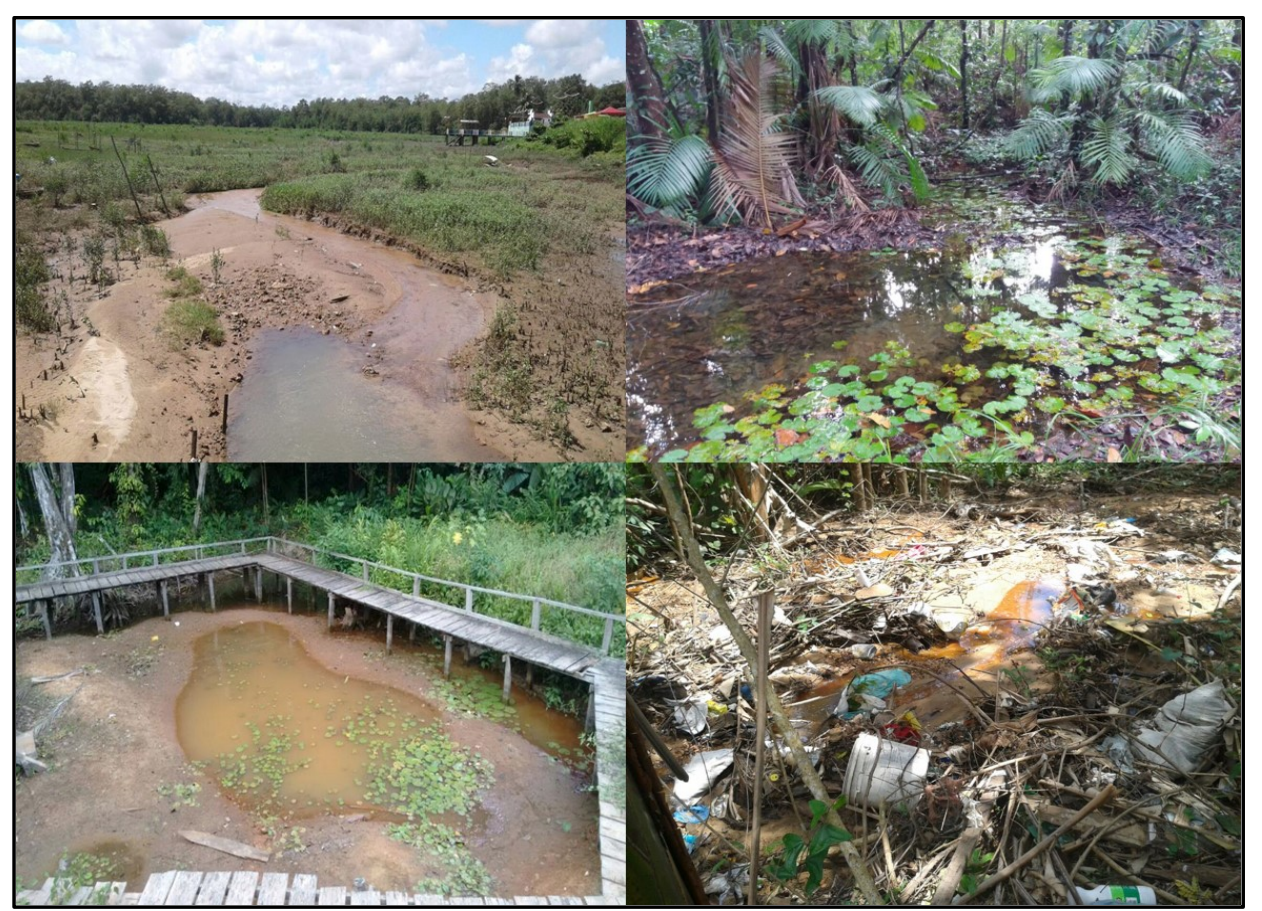

Fonte: Fotos cedidas pelo Comitê de Bacia Hidrográfica do Rio Marapanim (CBHRM)

Dentre as nascentes especificadas na Figura 7, duas delas (Igarapé do pouso - São Francisco do Pará e Rio das Pedras - Curuçá) também foram analisadas no estudo de Farias et al. (2020) ao realizarem um diagnóstico ambiental das nascentes da bacia hidrográfica do rio Marapanim (BHRM). Nesse estudo, as referidas nascentes foram enquadradas como de péssima qualidade ambiental, destacando-se os impactos associados à erosão e retirada da vegetação, descarte de resíduos sólidos, tendo como principal indicador de intervenção a proximidade com áreas de ocupação antrópica. $\mathrm{Na}$ nascente do rio das Pedras, identificou-se mortalidade de vida aquática (FARIAS et al., 2020).

A situação dos conflitos de uso da terra em APP's do nordeste paraense também foi verificada por Pereira et al. (2016), estudando a bacia hidrográfica do rio Peixe-boi. Esses autores constataram que as classes de pastagem e solo exposto foram responsáveis pelas maiores áreas conflitantes, seguido da agricultura.

A dinâmica de substituição de áreas vegetadas por outros usos ocasiona significativas alterações nos processos hidrológicos ao longo da bacia, levando a 
problemas socioambientais como erosão, assoreamento, enchentes, além de interferir na disponibilidade hídrica (COUTINHO et al., 2013), enfatizando assim, a extrema importância de preservação das APP's para a qualidade ambiental e, consequentemente, da vida humana.

A partir da Tabela 5 nota-se que em 2008 apenas 1,89 km² das APP's eram ocupadas por áreas alteradas, no entanto em 2017 essa área passou para 5,38 km², o que mostra a ocupação irregular das Áreas de Preservação Permanente da bacia hidrográfica, principalmente no ano mais recente.

A análise conjunta do uso e ocupação da terra nas APP's em todos os anos mostra que houve um aumento gradativo do percentual de ocupação irregular nas APP's. Em 1988 o uso inadequado somava $24,54 \%$ das ocupações, passando para $27,21 \%$ em 1998, atingindo 33,86\% em 2008 e finalmente em 2017 o uso irregular das APP's somam 35,97\% do uso do solo da bacia (Tabela 5). Quando comparado o primeiro ao último ano de análise, a ocupação irregular aumentou em 46,57\%.

\section{CONCLUSÕES}

O conflito de uso nas APP's da bacia hidrográfica do rio Marapanim ao longo dos anos de análise deu-se prioritariamente para a classe solo exposto, fato esse que demonstra que essas áreas estão sendo irregularmente desmatadas, o que vai de encontro ao que preconiza a legislação ambiental brasileira. O uso inadequado aumentou 46,57\% de 1988 a 2017, o que reflete a necessidade de maior fiscalização dessas áreas, bem como maior investimento na recuperação das áreas já impactadas.

O uso das ferramentas de geoprocessamento foi eficaz na caracterização e identificação dos conflitos de uso da terra nas APP's, ao mesmo tempo na verificação e aplicabilidade do código florestal brasileiro, que define a área mínima a ser destinada a preservação.

Assim, esse estudo pode subsidiar as ações de monitoramento e auxiliar o comitê de bacia hidrográfica do rio Marapanim na recuperação das nascentes e margens dos rios, promovendo assim, melhor gestão ambiental e planejamento territorial. 


\section{REFERÊNCIAS}

ALEXAKIS, D. et al. GIS and remote sensing techniques for the assessment of land use change impact on flood hydrology: the case study of Yialias basin in Cyprus. Nat. Hazards Earth Syst. Sci., v.14, p. 413-426, 2014.

ALVARES, C.A.; STAPE, J.L.; SENTELHAS, P.C.; GONÇALVES, J.L.M.de.; SPAROVEK, G., 2014. Ko "ppen's climate classification map for Brazil. Meteorologische Zeitschrift. v. 22, n.6, p.711-728, 2014.

ALMEIDA, A. S.de.; VIEIRA, I.S.G. Conflitos no uso da terra em Áreas de Preservação Permanente em um polo de produção de biodiesel no Estado do Pará. Rev. Ambient. Água. v.9, n.3, p.1-9, 2014.

ANDRADE, A.S.; RIBEIRO, S.C.A.; PEREIRA, B.W.F.; BRANDÃO, V.V.P. Fragmentação da vegetação da bacia hidrográfica do Rio Marapanim, nordeste do Pará. Ciência Florestal, v. 30, n. 2, p. 406-420, 2020.

BAKER, T.; MILLER, S. Using the Soil and Water Assessment Tool (SWAT) to assess land use impact on water resources in an East African watershed. Journal of Hydrology. v.486, p.100-111, 2013.

BUCK, O.; NIYOGI D. K.; TOWNSEND, C. R. Scale-dependence of land use effects on water quality of streams in agricultural catchments. Environmental Pollution, Braking. v.130, p.287-299, 2004.

BRASIL. Lei n. 12.651, de 25 de maio de 2012. Dispõe sobre a proteção da vegetação nativa; altera as Leis nos 6.938, de 31 de agosto de 1981, 9.393, de 19 de dezembro de 1996, e 11.428, de 22 de dezembro de 2006; revoga as Leis nos 4.771, de 15 de setembro de 1965, e 7.754, de 14 de abril de 1989, e a Medida Provisória no 2.166-67, de 24 de agosto de 2001; e dá outras providências. 2012. Diário Oficial da União, Brasília, DF, Ano CXLIX, n. 102, 28 maio 2012. Seção 1, p.1. Disponível em http://portal.in.gov.br/ . Acesso em 27 out. de 2017.

BORGES, L.A.C.; REZENDE, J.L.P.; PEREIRA, J.A.A.; JÚNIO, L.M.C.; BARROS, D.A. Áreas de preservação permanente na legislação ambiental brasileira. Cienc. Rural. v.41, n.7, p.1202-1210, 2011.

CARDOSO, J.A.; AQUINO, C.M.S. Mapeamento dos conflitos de uso nas Áreas de Preservação Permanente (APPs) da microbacia do riacho do Roncador, Timon (MA). Bol. Goia. Geogr., v.33, n.3, p.133-148, 2013.

CAMPAGNOLO, k.; SILVEIRA, G.L.; MIOLA, A.C.; SILVA, R.L.L. Área de preservação permanente de um rio e análise da legislação de proteção da vegetação nativa. Ciência Florestal, v.27, n.3, p.831-842, 2017. 
COCCO, J.; GALVANIN, E.A.S.; RIBEIRO, H.V.; NASCIMENTO, D.L. Análise do uso e cobertura da terra nas áreas de preservação permanente das nascentes da sub-bacia de Mato Grosso-Brasil. Ciência e Natura, v.38, n.3, p.1411-1418, 2016.

CORDEIRO, I.M.C.C.; ARBAGE, M.J.C.; SCHWARTZ, G. Nordeste do Pará: configuração atual e aspectos identitários. In: CORDEIRO, I.M.C.C.; RANGEL-VASCONCELOS, L.G.T.; SCHWARTZ, G.; OLIVEIRA, F.A. (Org.), Nordeste paraense: panorama geral e uso sustentável das florestas secundárias. Belém: Edufra; 2017. p. 19-58.

COUTINHO, L.M.; ZANETTI, S.S.; CACÍLIO, R.A.; GARCIA, G.O.; XAVIER, A.C. Usos da Terra e Áreas de Preservação Permanente (APP) na Bacia do Rio da Prata, Castelo-ES. Floresta e Ambiente, v.20, n.4, p.425-434, 2013.

CHAVEZ, P. S. An improved dark-object subtraction technique for atmospheric scattering correction of multispectral data. Remote Sensing of Environment, v.24, p.459-479, 1988.

CHAVEZ, P. S. Radiometric calibration of Landsat thematic mapper multispectral images. Photogrammetric Engineering and Remote Sensing, v.55, p.1285-1294, 1989.

EMBRAPA. Empresa Brasileira de Pesquisa Agropecuária, 2013. Sistema Brasileiro de Classificação de Solos. Brasília.

EMBRAPA - Empresa Brasileira de Pesquisa Agropecuária. Centro Nacional de Pesquisa de Solos (Rio de Janeiro, RJ). Sistema brasileiro de classificação de solos. - Rio de Janeiro: EMBRAPA-SPI, 2009.

FERREIRA, R.Q.S.; BATISTA, E.C.; SOUZA, P.A.; SOUZA, P.B.; SANTOS, A.F. Diagnóstico ambiental do córrego Mutuca, Gurupi - TO. Revista Verde, v.10, n.4, p.8-12, 2015.

FARIAS, M.G.S.; LIMA, A.M.M.; SILVA-JUNIOR, J.A. Manejo e conservação de nascentes na Bacia Hidrográfica do Rio Marapanim (PA). Revista Geonorte, v.11, n.37, p.78-96, 2020.

IBGE. Censo Demográfico 2010. IBGE - cidades. Disponível em: https://cidades.ibge.gov.br/ . Acesso em: 30 out. 2017.

IBGE. Instituto Brasileiro de Geografia e Estatística, 2012. Manual técnico da vegetação brasileira. Disponível: https://biblioteca.ibge.gov.br/visualizacao/livros/liv63011.pdf Acesso em: 30 out. 2017.

JUNIOR, R.F.do.V.; PASSOS, A.de.O.; ABDALA, V.L.; RAMOS, T.G. Determinação das Áreas de Preservação Permanente na bacia hidrográfica do rio Uberaba - MG, utilizando o Sistema de Informação Geográfica - SIG. Global Science and Technology, v.3, n.1, p.19-29, 2010.

KREITLOW, J.P.; SILVA, J.S.V.; NEVES, S.M.A.S.; NEVES, R.J.; NEVES, L.F.S. Vulnerabilidade Ambiental e Conflito no Uso da Terra no município de Mirassol d'Oeste, Brasil. Revista Brasileira de Cartografia, n.68/10, p.1917-1936, 2016. 
LANDIS, J.R.; KOCH, G.G. The measurement of observer agreement for categorical data. Biometrics, v.33, n.1, p.159-174, 1977.

MARTORANO, L.G.; PEREIRA, L.C.; CESAR, E.G.M.; PEREIRA, I.C.B. Estudos climáticos do Estado do Pará, classificação climática (Köppen) e deficiência hídrica (ThornthwhiteMather). Belém: SUDAM; Rio de Janeiro: EMBRAPA-SNLCS, 1993. 53 p.

MOREIRA, T.R.; SANTOS, A.R.; DALFI, R.L.; CAMPOS, R.F.; SANTOS, G.M.A.D.A.; EU GENIO, F.C. Confronto do Uso e Ocupação da Terra em APPsno Município de Muqui, ES. Floresta e Ambiente, v.22, n.2, p.141-152, 2015.

MARTINI, L.C.P.; TRENTINI, E.C. Agricultura em zonas ripárias do sul do Brasil: conflitos de uso da terra e impactos nos recursos hídricos. Soc. Estado, v.26, n.3, p. 613-630, 2011.

NOVO, E.M.L.M. Sensoriamento remoto: princípios e aplicações, 4.ed. São Paulo: Edgard Blucher; 2010.

OLIVEIRA, F.S.; SOARES, V.P.; PEZZOPANE, J.E.M.; GLERIANI, J.M.; LIMA, J.S.; SILVA, E.; RIBEIRO, C.A.A.S.; OLIVEIRA, A.M.S. Identificação de conflito de uso da terra em Áreas de Preservação Permanente no entorno do Parque Nacional do Caparaó, estado de Minas Gerais. R. Árvore, v.32, n.5, p.899-908, 2008.

OLIVEIRA, D.G.; VARGAS, R.R.; SAAD, A.R.; ARRUDA, R.O.; DALMAS, F.B.; AZEVEDO, F.D. Land use and its impacts on the water quality of the Cachoeirinha Invernada Watershed, Guarulhos (SP). Rev. Ambient. Água, v.13, n.1, p.21-31, 2018.

PARA, 2019. DECRETO N² 288, DE 3 DE SETEMBRO DE 2019. Institui o Comitê da Bacia Hidrográfica do Rio Marapanim (CBHRM), e dá outras providências. Acesso em: 12 nov. 2020. Disponível em: http://www.ioepa.com.br/pages/2019/09/04/2019.09.04.DOE_4.pdf

PINTO, L.V.A.; FERREIRA, E.; BOTELHO, S.A.; DAVIDE, A.C. Caracterização física da bacia hidrográfica do Ribeirão Santa Cruz, Lavras, MG e uso conflitante da terra em suas Áreas de Preservação Permanente. Cerne, v.11, n.1, p.49-60, 2005.

PEREIRA, B.W.F.; MACIEL, M.N.M.; OLIVEIRA, F.A.; ALVES, M.A.M.S., RIBEIRO, A.M.; FERREIRA, B.M.F.; RIBEIRO, E.G.P. Uso da terra e degradação na qualidade da água na bacia hidrográfica do rio Peixe-Boi, PA, Brasil. Rev. Ambient. Água, v.11, n.2, p.472-485, 2016.

SANTOS, J.B.; FILHO, J.C.P.; DANTA, M.J.F.; ZIMBACK, C.R.L.; LESSA, L.G.F. Avaliação da adequação da ocupação do solo em Áreas de Preservação Permanente (APPs). Irriga, v.19, n.2, p.333-344, 2014.

SANTOS, L.B.; COELHO, A.S.; BARROS, M.N.R.; FENZL, N.; CANTO, O.; VIEIRA, I.C.G.; ADAMI, M.; GOMES, A.R. Usos da terra e conservação da biodiversidade na bacia hidrográfica do Rio Marapanim, Pará. Revista Brasileira de Geografia Física, v.12, n.3, p. 929-943, 2019. 
SOUZA, S.R.; MACIEL, M.N.M.; OLIVEIRA, F.A.; JESUÍNO, S.A. Caracterização do conflito de uso e ocupação do solo nas Áreas de Preservação Permanente do rio Apeú, Nordeste do Pará. Floresta, v.42, n.4, p.701-710, 2012.

VENTURIERI, A.; FIGEIREDO, R.; WATRIN, O. S.; MARKEWITZ, D. Utilização de imagens Landsat e CBERS na avaliação da mudança do uso e cobertura da terra e seus reflexos na qualidade da água em microbacia hidrográfica do município de Paragominas, Pará. In: Simpósio Brasileiro De Sensoriamento Remoto, 12., 2005, Goiânia. Anais. São José dos Campos: INPE, 2005. v. 1., p. 1127-1134.

\section{CONTRIBUIÇÕES DE AUTORIA}

\section{1 - Ádanna de Souza Andrade}

Graduada em Engenharia Ambiental e Energias Renováveis, Especialista em georreferenciamento de imóveis rurais e Mestre em Ciências Ambientais pelo Programa de Pós-Graduação em Ciências Ambientais da Universidade do Estado do Pará. Atualmente é professora do Ensino Básico, Técnico e Tecnológico do Instituto Federal do Pará, campus Itaituba.

https://orcid.org/0000-0002-7516-3862 - adanna.souza@ifpa.edu.br

Contribuição: Conceituação, Escrita - rascunho original, Análise formal e Supervisão

\section{2 - Suezilde da Conceição Amaral Ribeiro}

Possui graduação em Engenharia Química, especialização em Tecnologia de Alimentos, mestrado em Engenharia de Alimentos e doutorado em Engenharia de Alimentos pela Universidade Estadual de Campinas. . É professora D4 do Instituto Federal de Educação, Ciência e Tecnologia do Pará- Campus Belém, atuando no Curso de graduação de Ciências Biológicas e nos cursos de Mestrado Profissional em Propriedade Intelectual e Transferência de Tecnologia para a Inovação e de Desenvolvimento Rural e Gestão de Empreendimentos Agroalimentares. É professora adjunta da Universidade do Estado do Pará do curso de graduação em Tecnologia de Alimentos e professora colaboradora da Universidade Federal do Pará no curso de Mestrado em Ciência e Tecnologia de Alimentos.

https://orcid.org/0000-0002-1661-7609 - suziar@yahoo.com.br

Contribuição: Escrita - Revisão e edição

\section{3 - Bruno Wendell de Freitas Pereira}

Possui Graduação em agronomia, Mestrado em Ciências Florestais, e Doutorado em Ciências Agrárias pela Universidade Federal Rural da Amazônia. Atualmente é Professor Efetivo Adjunto da Universidade Federal Rural da Amazônia. https://orcid.org/0000-0002-3823-6292 -brunowendell@yahoo.com.br Contribuição: Escrita - Revisão e edição 


\section{4 - Paulo Eduardo Silva Bezerra}

Possui Graduação em Engenharia Ambiental e Energias Renováveis. Atualmente é Mestrando em Engenharia Civil com ênfase na Engenharia Hídrica pela Universidade Federal do Pará e está se especializando em Georreferenciamento de Imóveis Rurais no Instituto de Pós-graduação e Cursos.

https://orcid.org/0000-0001-5424-6012 - pauloeduardoea@yahoo.com.br Contribuição: Análise formal

\section{5 - Valter Vinicius Pereira Brandão}

Possui Graduação em Geografia (Licenciatura), especialização em Geografia da Amazônia. Atualmente é professor da disciplina Geografia na Secretaria de Estado de Educação do Estado do Pará.

https://orcid.org/0000-0003-0924-2885 - viniciuspgeo@gmail.com

Contribuição: Análise formal

\section{Como citar este artigo}

ANDRADE, Á. S.; RIBEIRO, S. C. A.; PEREIRA, B. W. F.; BEZERRA, P. E. S.; BRANDÃO, V. V. $P$. Conflito de uso do solo em Áreas de Preservação Permanente da Bacia Hidrográfica do rio Marapanim, nordeste do Pará. Ciência e Natura, Santa Maria, v. 43, e20, p. 1 21, 2021. Disponível em: https://doi.org/10.5902/2179460X43036. Acesso em: dia, mês (abreviado), ano. 